\title{
Fatigue Crack Growth Behaviour and Role of Roughness-Induced Crack Closure in CP Ti: Stress Amplitude Dependence
}

\author{
Mansur Ahmed ${ }^{1, *}$, Md. Saiful Islam ${ }^{2}$, Shuo Yin ${ }^{1}$, Richard Coull $^{1}$ and Dariusz Rozumek ${ }^{3}$ (D) \\ 1 Department of Mechanical, Manufacturing and Biomedical Engineering, Trinity College Dublin, \\ The University of Dublin, D02 DA31 Dublin, Ireland; yins@tcd.ie (S.Y.); rncoull@live.com (R.C.) \\ 2 Department of Glass and Ceramic Engineering, Bangladesh University of Engineering and Technology, \\ Dhaka 1000, Bangladesh; mdsaiful@gce.buet.ac.bd \\ 3 Faculty of Mechanical Engineering, Opole University of Technology, Mikolajczyka 5, 45-271 Opole, Poland; \\ d.rozumek@po.edu.pl \\ * Correspondence: maahmed@tcd.ie or ma960@uowmail.edu.au; Tel.: +353-1-896-2396
}

Citation: Ahmed, M.; Islam, M.S.; Yin, S.; Coull, R.; Rozumek, D.

Fatigue Crack Growth Behaviour and

Role of Roughness-Induced Crack Closure in CP Ti: Stress Amplitude Dependence. Metals 2021, 11, 1656. https: / / doi.org/10.3390/

met11101656

Academic Editor: Denis Benasciutti

Received: 16 September 2021

Accepted: 18 October 2021

Published: 19 October 2021

Publisher's Note: MDPI stays neutral with regard to jurisdictional claims in published maps and institutional affiliations.

\begin{abstract}
This paper investigated the fatigue crack propagation mechanism of $\mathrm{CP} \mathrm{Ti}$ at various stress amplitudes $(175,200,227 \mathrm{MPa})$. One single crack at $175 \mathrm{MPa}$ and three main cracks via sub-crack coalescence at $227 \mathrm{MPa}$ were found to be responsible for fatigue failure. Crack deflection and crack branching that cause roughness-induced crack closure (RICC) appeared at all studied stress amplitudes; hence, RICC at various stages of crack propagation $(100,300$ and $500 \mu \mathrm{m})$ could be quantitatively calculated. Noticeably, a lower RICC at higher stress amplitudes (227 MPa) for fatigue cracks longer than $100 \mu \mathrm{m}$ was found than for those at $175 \mathrm{MPa}$. This caused the variation in crack growth rates in the studied conditions.
\end{abstract}

Keywords: CP Ti; stress amplitude; fatigue crack propagation; crack growth rate; roughness-induced crack closure

\section{Introduction}

Commercially pure titanium (CP Ti) possesses high ductility as well as excellent corrosion resistance and biocompatibility properties; hence, it has been used in the chemical and biomedical industries, especially in reactor container in chemical plants, and in power station heat exchangers [1]. In these environments, cyclic loading is applied to the components. Therefore, investigation of the fatigue behaviour of $\mathrm{CP}$ Ti becomes an important research subject. Fatigue crack initiation, growth, closure and fractography are critical features describing fatigue behaviour. A fatigue crack path may be a powerful resource determining all the aforementioned features. For instance, roughness-induced crack closure (RICC) is attributed to crack path deflection, especially near the threshold range, at which a serrated or zigzag crack path is induced by microstructure-sensitive crack growth [2-4]. The tilt angle of the crack path in $2124 \mathrm{Al}$ alloy is reported to be a key controlling factor for RICC [5]. Wang and Müller [2,6] reported that RICC occurs due to a serrated crack path, which significantly affects crack growth rates in Ti-2.5 $\mathrm{Cu}(\mathrm{wt} \%)$ and TIMETAL 1100 alloys. Fatigue crack growth rates are reported to be decreased by crack path deflection $[3,4,7]$, as the crack path causes a direct reduction of the local driving force for crack propagation and an increase in the total crack path length, which results in lower crack growth rates and induces RICC. Antunes et al. [8] mentioned that cracks with larger path deflection may result in higher mode II displacement between the two fracture surfaces, causing higher crack closure stress intensity [9]. Ding et al. [10] correlated the fatigue crack profile with fatigue crack growth rate in Ti-6Al-4V and Ti-4.5Al-3V-2Mo-2Fe alloys. Okayasu et al. [11] investigated the influence of fatigue loading conditions such as, stress amplitude and stress ratio on the contact features of fracture surfaces in annealed Carbon Steel via two 
methods: (1) Collecting fracture debris fallen from the crack surfaces; and (2) Observing the fracture surface directly through the replica technique. They showed that the fatigue stress amplitude and stress ratio played major factors in determining the contact status between the mating fracture surfaces, e.g., a larger stress amplitude and smaller stress ratio lead to stronger fracture surface contact or interaction. Student et al. [12] studied the role of fracture surface roughness on crack closure in long-term exploited heat-resistant steel. They reported that shear processes at the tip of a fatigue crack significantly affect crack closure and contribute to the roughness of the fracture surface.

The above discussions evidently show that fatigue crack path can be effectively used to investigate numerous phenomena. Unfortunately, study on the fatigue behaviour of CP Ti related to crack path and its role in detecting fatigue phenomena such as RICC is totally lacking in the literature. To fill this gap, the fatigue crack growth mechanism and corresponding RICC from fatigue crack path in CP Ti has been revealed here. This will further help in understanding fatigue crack growth at the small crack regime and the role of RICC in such cracking.

\section{Materials and Methods}

The composition of the studied CP Ti is given in Table 1. A vacuum furnace heattreatment of the as received hot rolled sample was performed at $700{ }^{\circ} \mathrm{C}$ for $30 \mathrm{~min}$ for obtaining equiaxed $\alpha$ grains. Following heat treatment, samples were machined in order to prepare fatigue specimen with the dimensions shown in Figure 1. Because the surface condition of the specimen in fatigue testing is very sensitive, the samples were then carefully mechanically polished using various grades of $\mathrm{SiC}$ emery papers followed by colloidal silica with hydrogen peroxide solution. The polished surfaces were then etched using Kroll's reagent $\left(3 \mathrm{HF}: 6 \mathrm{HNO}_{3}: 91 \mathrm{H}_{2} \mathrm{O}\right)$ to reveal the microstructure.

Table 1. Chemical composition (in $\mathrm{wt} \%$ ) of the CP Ti.

\begin{tabular}{cccc}
\hline Ti & O & H & Fe \\
\hline Balance & 0.078 & 0.005 & 0.026 \\
\hline
\end{tabular}

(a)

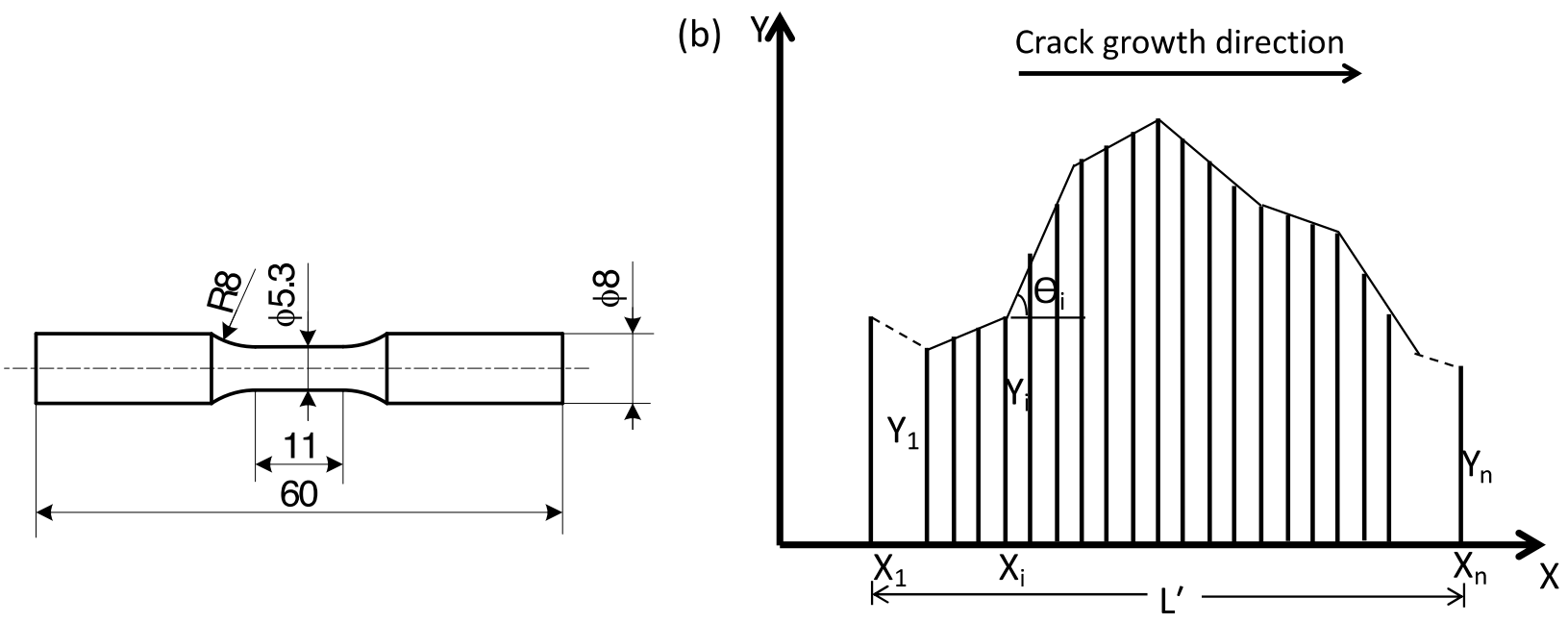

Figure 1. (a) Schematic of sample with the dimensions used for the rotating bending test (dimensions in $\mathrm{mm}$ ); (b) Ycoordinates along the crack path profile with equidistant spacing.

Tensile tests of CP Ti samples were performed employing an Instron Universal Tensile Machine. The dimensions of the samples were in accordance with the ASTM E8. For each condition, three samples are tested, at room temperature and at a strain rate of $1 \mathrm{~mm} / \mathrm{min}$. 
An Ono-type rotating bending fatigue machine was used for fatigue tests, at a frequency of $30 \mathrm{~Hz}$. A stress interval of $25 \mathrm{MPa}$ was chosen, from the fatigue limit to a stress at which the distinction of the stress amplitude effect could be numerated. Consequently, fatigue tests at the stresses of 175, 200 and $227 \mathrm{MPa}$ were conducted. The stress ratio (R) was -1 with sinusoidal wave form. All tests were conducted at temperature from $15-20{ }^{\circ} \mathrm{C}$. During testing, a cooling fan was used to cool the specimens, as heat production affects the deformation mechanism of Ti. During fatigue testing, the replica technique was intermittently used at different cycles to trace out crack initiation and propagation; this technique involved immersing replica films into methyl acetate solution and subsequently pasting them onto the specimen surface. To then acquire the image from the replica sheet, an optical microscope (VHX-2000 series, Keyence, Osaka, Japan) was used. One sample of each condition was investigated. Following the fatigue tests, fractographic analysis was conducted using a JEOL IT-300 (JEOL, Tokyo, Janpa) scanning electron microscope (SEM) at an acceleration voltage of $30 \mathrm{kV}$.

Roughness parameters were quantitatively measured using the surface crack paths along the fractured specimens. Two roughness parameters, (i) linear roughness parameter $\left(\mathrm{R}_{\mathrm{L}}\right.$ ) and (ii) arithmetic mean deflection angle $(\bar{\theta})$, were evaluated using the equidistant spacing method $[3,4,13]$. Figure $1 \mathrm{~b}$ displays the equidistant spacing method used to calculate these roughness parameters. The details of this method can be found elsewhere [3].

The linear roughness parameter, $\mathrm{R}_{\mathrm{L}}$ of a crack profile is defined as follows:

$$
\mathrm{R}_{\mathrm{L}}=\mathrm{L} / \mathrm{L}^{\prime}
$$

where $\mathrm{L}$ and $\mathrm{L}^{\prime}$ correspond to the true length and projected length of the crack profile, respectively. The arithmetic mean deflection angle of a crack profile is given below:

$$
\bar{\theta}=\frac{1}{n} \sum_{\mathrm{i}=1}^{\mathrm{n}}\left|\theta_{\mathrm{i}}\right|
$$

where $\theta_{\mathrm{i}}$ represents the angle between the profile element and X-coordinate axis and can have either a positive or a negative value $\left(90^{\circ} \leq \theta \leq-90^{\circ}\right)$, depending on the crack profile.

\section{Results}

\subsection{Initial Microstructure, and Tensile and Fatigue Properties}

Figure 2a shows the initial microstructure of the studied material. Uniformly distributed (hexagonal closed packed) $\alpha$ grains with an average diameter of $\sim 35 \mu \mathrm{m}$ can be observed. The size of the $\alpha$ grains was calculated using Image J. The engineering stressstrain curve plotted from the tensile test is shown in Figure 2b. Beyond the yielding point, work-hardening is followed by work-softening along the stress-strain curve. The yield strength (YS), ultimate tensile strength (UTS) and total elongation (El.) of the studied material were measured to be $293 \pm 12 \mathrm{MPa}, 383 \pm 7 \mathrm{MPa}$ and $67 \pm 1 \%$, respectively. Table 2 shows the fatigue test results at various stress amplitudes. As expected, the total life cycle was found to be reduced with increasing stress amplitude. For instance, the sample tested at $175 \mathrm{MPa}$ survived for $6.94 \times 10^{5}$ cycles, while the sample tested at $227 \mathrm{MPa}$ only lasted for $1.05 \times 10^{5}$ cycles. At the intermediate stress amplitude of $200 \mathrm{MPa}$, the sample failed after reaching $3.4 \times 10^{5}$ cycles. 


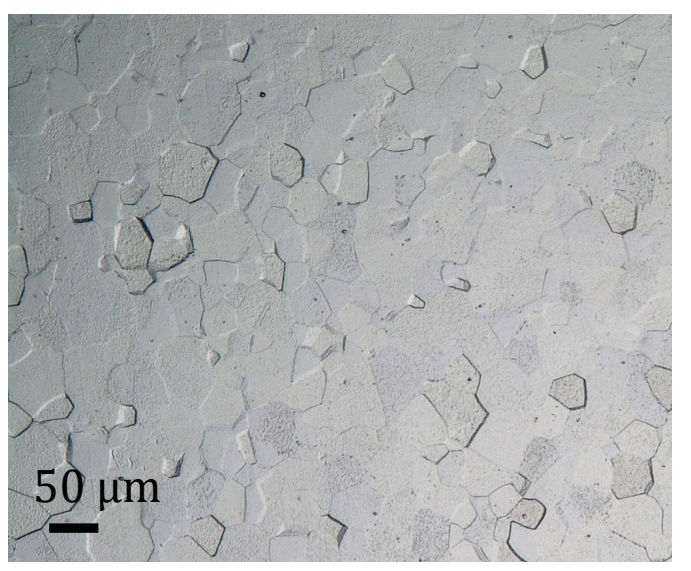

(a)

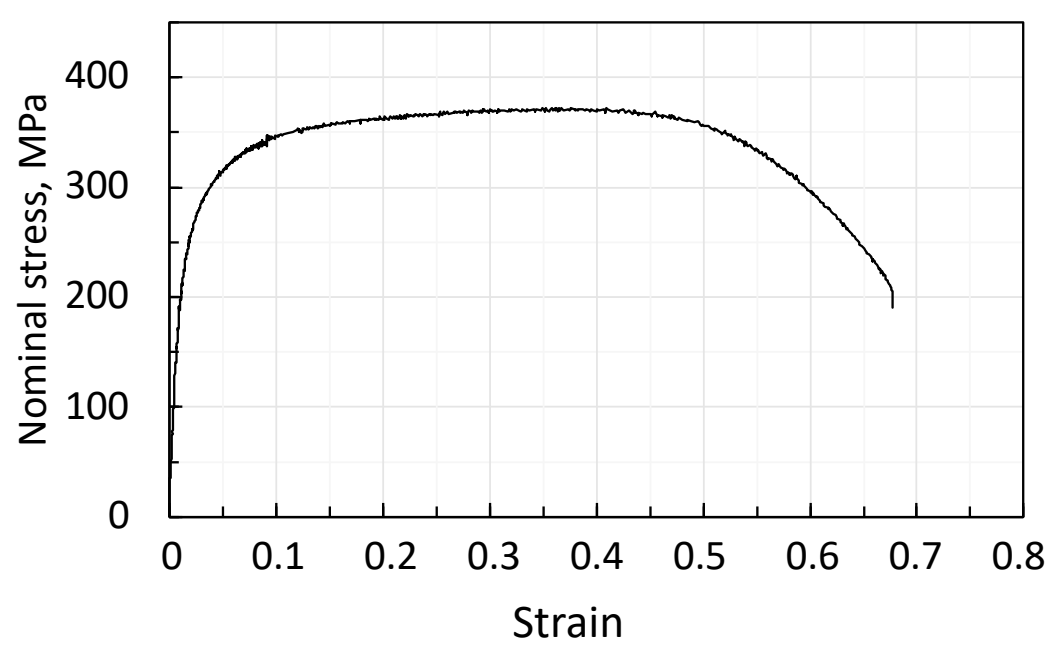

(b)

Figure 2. (a) Initial microstructure; (b) Representative stress-strain curve of the studied CP Ti.

Table 2. Summary of fatigue tests results obtained in this study.

\begin{tabular}{ccc}
\hline Stress Amplitude, MPa & $\begin{array}{c}\text { Crack Initiation Cycle } \\
\left(\times \mathbf{1 0}^{5}\right)\end{array}$ & Total Life Cycle $\left(\times \mathbf{1 0}^{\mathbf{5}}\right)$ \\
\hline 175 & $1.0-2.0$ & 6.94 \\
200 & $0.5-1.0$ & 3.40 \\
227 & $0.2-0.3$ & 1.05 \\
\hline
\end{tabular}

\subsection{Fatigue Crack Nucleation and Propagation, Propagation Rate and Fractography}

Figure 3 shows optical micrographs of the fatigue surface crack and its surroundings at various cycles at $175 \mathrm{MPa}$. The microstructure in Figure 3a shows an image taken before the test corresponding to a region where the main fatigue crack initiated. After $2 \times 10^{5}$ cycles, a micro-sized crack located inside an $\alpha$ grain can be seen (Figure $3 b$ ). This indicates that the crack initiated between $1 \times 10^{5}-2 \times 10^{5}$ cycles, as no crack was found after $1 \times 10^{5}$ cycle (not shown here). Therefore, it is evident that most of the fatigue lifecycle was consumed by fatigue crack propagation considering total fatigue life $\left(6.94 \times 10^{5}\right.$ cycles $)$. Crack propagation and its features after $4 \times 10^{5}$ cycles can be observed in Figure 3c, and was predominantly transgranular in nature and thus deflected by almost every grain. Following $6 \times 10^{5}$ cycles (Figure 3d), crack propagation was incremental, continuing in transgranular mode. Some important fatigue crack propagation features, such as crack branching (Figure 3f,h) and fine scale zig-zag (Figure $3 \mathrm{e}-\mathrm{h}$ ) can also be seen. Some lines, presumably slip bands and/or deformation twinning, according to [14], appear in some grains (Figure $3 \mathrm{f}, \mathrm{h}$ ). Interactions between the crack and those lines confirm that cracking propagated along or across these slip bands/deformation twinning. Ismarrubie and Sugano [15] have also reported such lines belonging to slip bands. While crack branching in Figure $3 \mathrm{f}$ is transgranular, intergranular cracking also appears in Figure $3 \mathrm{~h}$. 

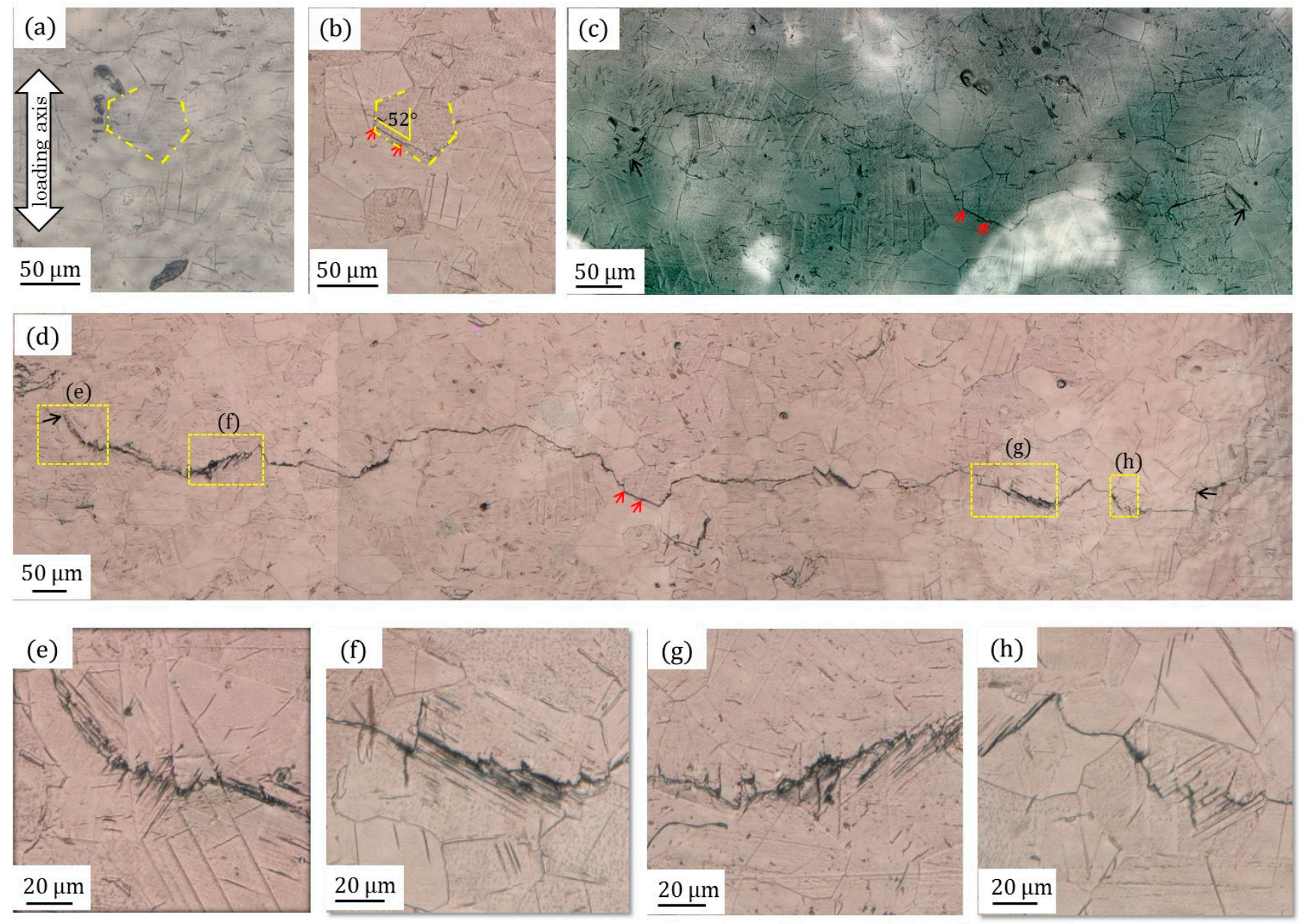

Figure 3. At $175 \mathrm{MPa}$ : Images showing surface crack paths at different cycles: (a) Initial condition, i.e., $\mathrm{N}=0$ cycle; (b) After $\mathrm{N}=2 \times 10^{5}$ cycles; (c) After $\mathrm{N}=4 \times 10^{5}$ cycles; (d) After $\mathrm{N}=6 \times 10^{5}$ cycles. The free-shape object in (a) and (b) indicates a particular area where the crack started. The red arrows illustrate crack initiation sites, and black arrows delineate the crack tips. Examples of fine zig-zag $(\mathbf{e}, \mathbf{g})$, crack branching $(\mathbf{f}, \mathbf{g})$, and crack interactions with slip bands (e,h).

Figure 4 delineates the initiation and subsequent propagation of the main crack at various cycles at $227 \mathrm{MPa}$. Figure 4 a illustrates the main fatigue crack, with a zig-zag pattern, after $1 \times 10^{5}$ cycles. This crack has been sectioned to understand its propagation mechanism. There are three sub-cracks labeled 1-3 connected to the main crack. Sub-cracks were labeled according to their connecting sequence with the main crack. Therefore, it can be seen that the fatigue crack of $\mathrm{CP}$ Ti tested at higher stress amplitude (227 MPa) grew by coalescing sub-cracks. Figure $4 \mathrm{~b}$ shows the main crack after $0.4 \times 10^{5}$ cycles, with the crack initiation site marked by red arrows. It is worth mentioning that the crack initiated between $0.2 \times 10^{5}-0.3 \times 10^{5}$ cycles, as there was no crack at $0.2 \times 10^{5}$ cycles (not shown here). Similar to the sample tested at $175 \mathrm{MPa}$, this condition also consumed majority of the total cycle of crack growth. Figure 4c-e show micrographs after $0.5 \times 10^{5}, 0.7 \times 10^{5}$ and $0.9 \times 10^{5}$ cycles, respectively, where pre-coalescence of the sub-cracks with the main crack are shown. Unlike the crack at $175 \mathrm{MPa}$, the crack at $227 \mathrm{MPa}$ preferably propagated via coalescing sub-cracks. This is the first time we saw such a difference in crack propagation mechanism with respect to the stress amplitude in CP Ti. Of the fatigue characteristics, a zig-zag nature and fine-scale crack branching are also visible under this condition. As at $175 \mathrm{MPa}$, a transgranular fracture mode was also predominant in this case. It is worth mentioning that crack propagation behavior at $200 \mathrm{MPa}$ was identical to that at $227 \mathrm{MPa}$. 

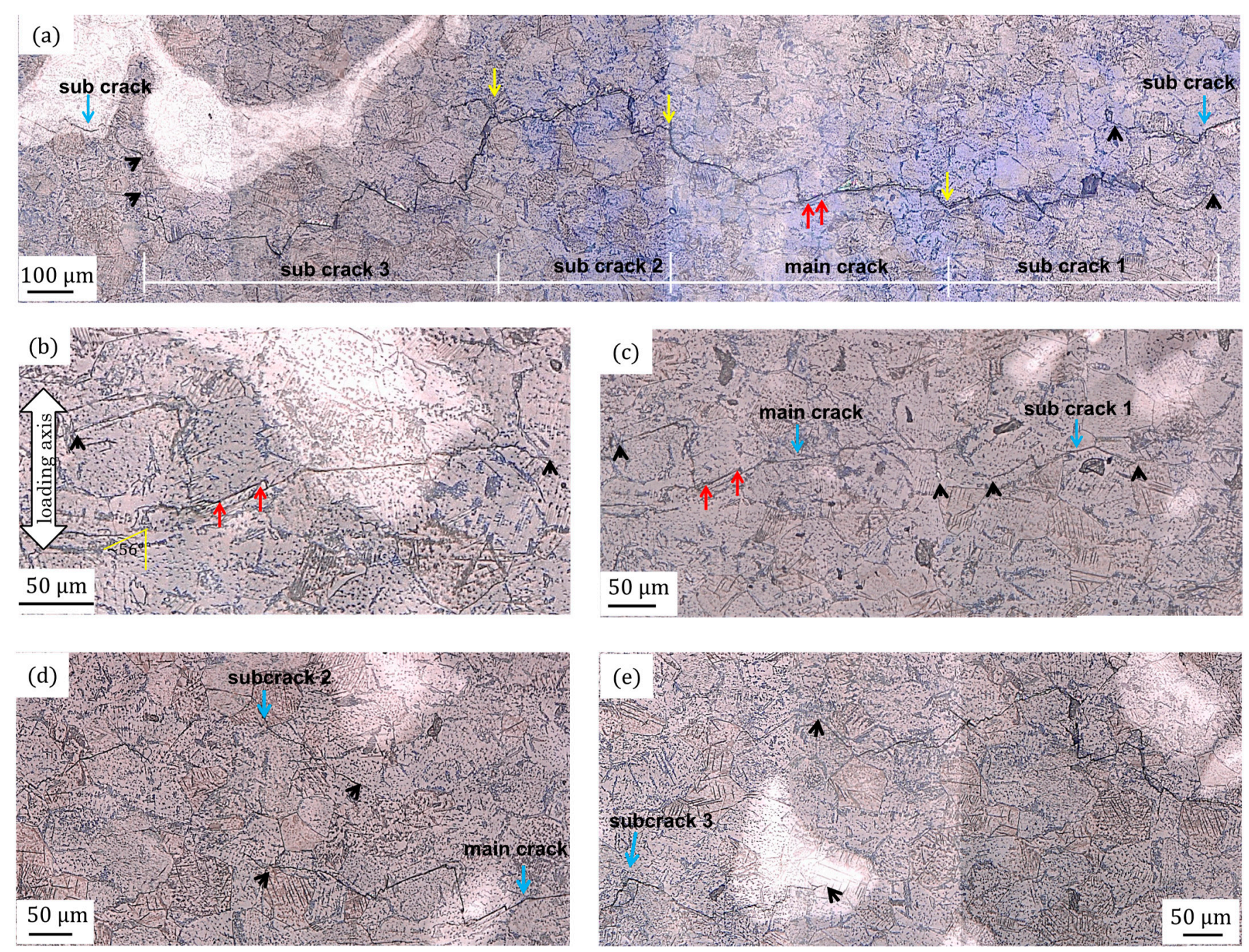

Figure 4. At $227 \mathrm{MPa}$ : Images displaying crack paths at different cycles. After (a) $\mathrm{N}=1 \times 10^{5}$ cycles; (b) $\mathrm{N}=0.4 \times 10^{5}$ cycles; (c) $\mathrm{N}=0.5 \times 10^{5}$ cycles; (d) $\mathrm{N}=0.7 \times 10^{5}$ cycles; (e) $\mathrm{N}=0.9 \times 10^{5}$ cycles. Red arrows show the crack initiation line, while black arrows indicate crack tips; (c) shows the main crack and sub-crack 1 before coalescing, while the main crack and sub-crack 2 can be seen in (d); (e) shows the main crack and sub-crack 3 prior to coalescence. The yellow arrows in (a) indicate the junctions of crack coalescence.

Figure 5 shows the relationship between crack length and number of cycles, as well as crack propagation rate with respect to the crack length. These data have been calculated based on the crack paths shown in Figures 3 and 4. While the crack length in the $175 \mathrm{MPa}$ sample grows steadily, crack length at $227 \mathrm{MPa}$ increases abruptly after around $300 \mu \mathrm{m}$ (Figure 5a). On the other hand, the crack growth rate in the $227 \mathrm{MPa}$ sample is significantly higher than that of the $175 \mathrm{MPa}$ sample for cracks longer than $100 \mu \mathrm{m}$. Figure 6 shows the fracture surfaces of the samples tested at various stress amplitudes. Three main features, including (i) crack initiation site (marked with green boxes), (ii) crack propagation, and (iii) the final fracture as dimples can be observed in each sample. Higher magnification images of the crack initiation sites are shown in Figure 6d-f. Interestingly, the position of the dimples progressively moves toward centre of the sample with increased stress amplitude. This corresponds to the number of cracks responsible for fracture with stress amplitude; for instance, one single crack, two cracks and three cracks were responsible for fracture of samples tested at 175, 200 and $227 \mathrm{MPa}$, respectively. 


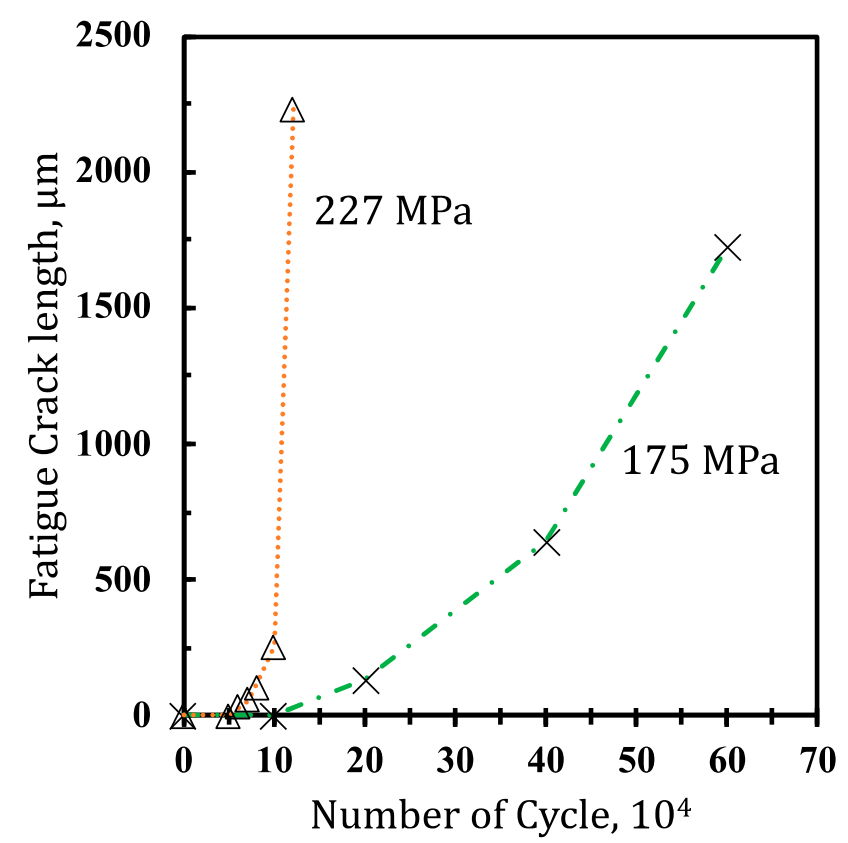

(a)

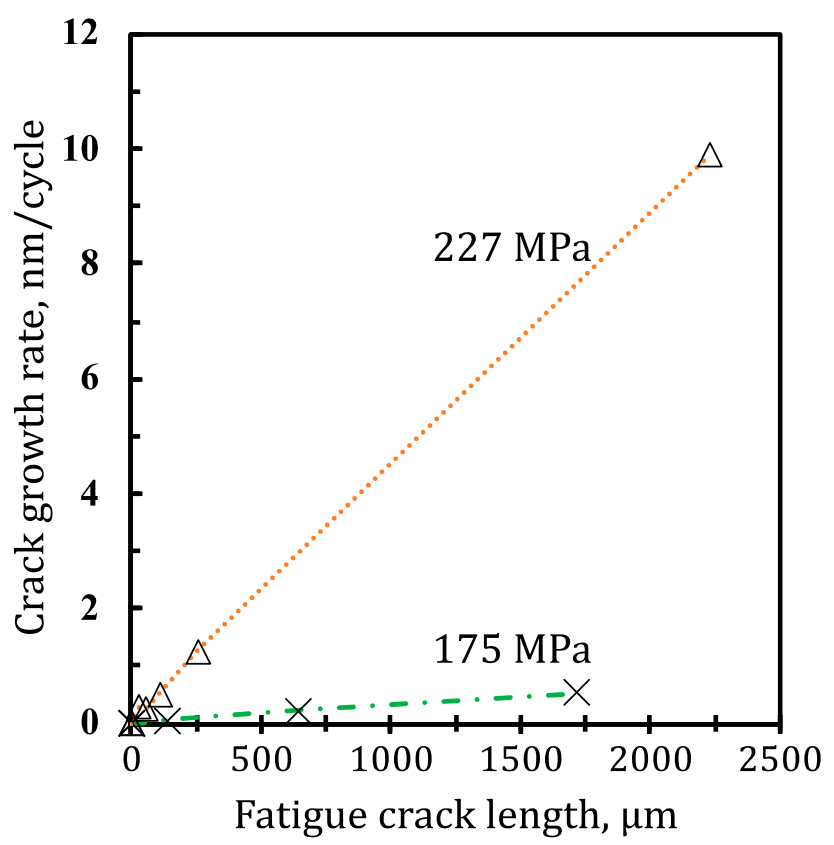

(b)

Figure 5. (a) Relationship between fatigue crack length and number of cycles; (b) Crack growth rate with respect to fatigue crack length.

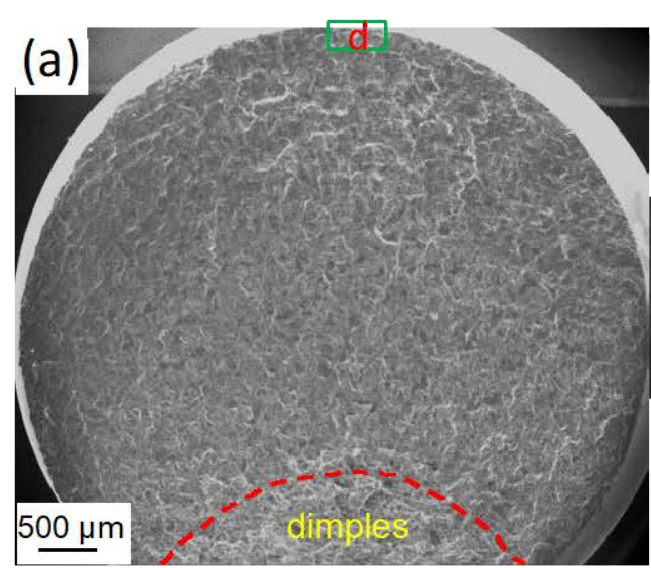

(d)

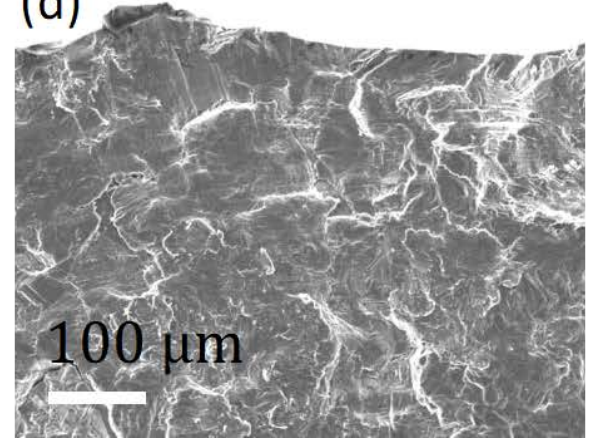

(b)

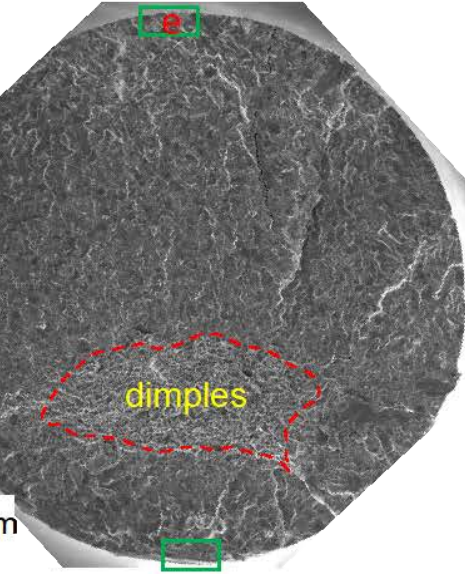

(e)

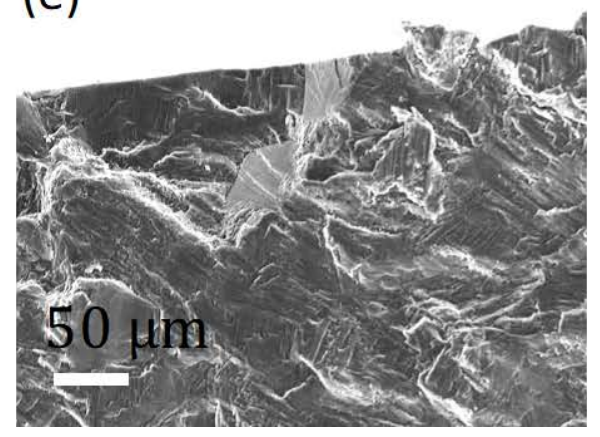

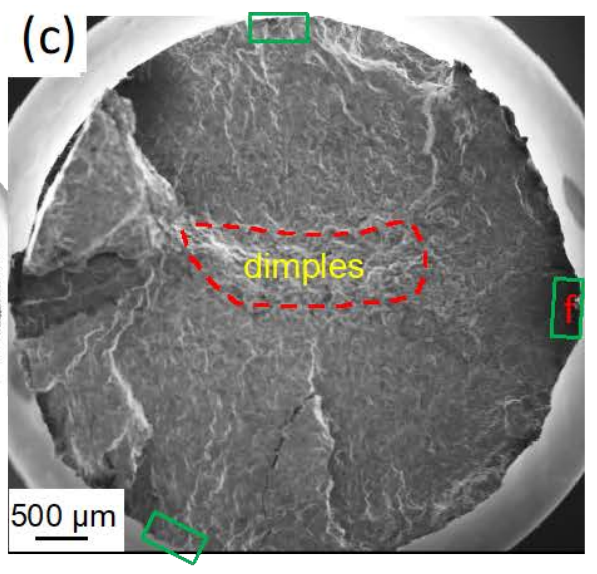

(f)

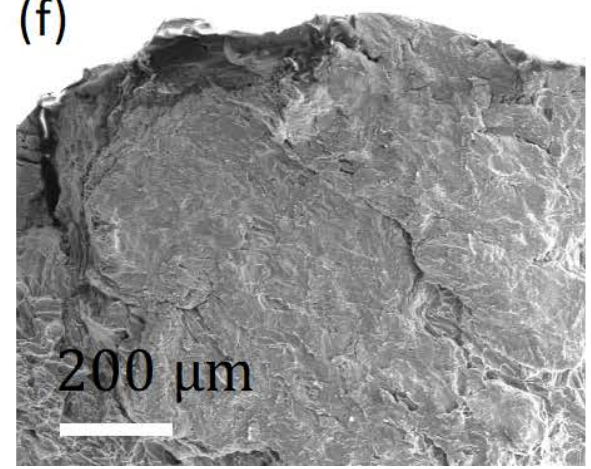

Figure 6. Fractography of the samples tested at (a) 175, (b) 200, and (c) $227 \mathrm{MPa}$. Green boxes indicate the nucleation sites of the main cracks. Crack nucleation sites for (d) 175, (e) 200, and (f) $227 \mathrm{MPa}$ stress conditions. 


\section{Discussion}

\subsection{Fatigue Crack Initiation and Propagation}

Fatigue cracks at various stress amplitudes evidently initiated from the surfaces of the specimens (Figure $6 \mathrm{~d}-\mathrm{f}$ ). This is consistent with earlier claims that fatigue cracks in Ti and its alloys tend to initiate from surface in the case of continuous cyclic loading if the surface is free of residual stress [16]. In this study, mechanical polishing followed by chemical etching was performed in order to ensure a residual stress-free surface so that crack would start from specimen surface. The measured angle of $\sim 50^{\circ}$ (Figures $3 \mathrm{~b}$ and $4 \mathrm{~b}$ ) between crack initiation and the loading axis is close to that of the maximum critical resolved shear stress $\left(45^{\circ}\right)$. The cracks thereafter propagated along a direction of approximately $70^{\circ}$ with respect to the loading axis, which is corresponded to mixed mode I and mode II crack growth. Close examination of crack path shows that a significant portion of the cracks propagated as zig-zag where the crack paths moved along or across slip bands/deformation twinning in short distances (Figure 4e-h). Such zig-zag phenomenon has been attributed to the alternative branching mode I and mode II in forged VT3-1 alloy [17]. Some portion of the crack propagated along the direction perpendicular to the loading axis, corresponding to mode II. It has been mentioned in $[18,19]$ that a shift in direction perpendicular to the specimen may sometimes appear in crack branching. This is consistent with the results shown in Figure 4f. The nature of the crack path is likely not dependent on the stress amplitude, while the number of cracks causing failure is highly dependent upon the stress amplitude. At $175 \mathrm{MPa}$, a single crack was responsible for failure, whereas at higher stress amplitudes the number of cracks that are responsible for failure increases. For instance, two cracks and three cracks nucleated at different stages in samples tested at 200 and $227 \mathrm{MPa}$ (Figure $3 b, c)$, respectively. Each of the main crack propagated via the sub-crack coalescence mechanism (Figure 5). Therefore, it can be claimed that fatigue crack nucleation and their propagation in CP Ti are largely dependent on the stress amplitude.

\subsection{Role of Roughness Induced Crack Closure (RICC)}

It is established that crack tortuosity, crack branching or their combination induce crack closure, as they promote higher roughness [19]. In this study, we have seen crack deflections with a zig-zag nature, crack branching, and a directional shift perpendicular to the specimen surrounding crack branching. Therefore, it is assumed that RICC has played a role in crack propagation. As such, the RICC for 175 and $227 \mathrm{MPa}$ samples has been calculated; the stress amplitude dependence of RICC is discussed below.

A model proposed by Pokluda and Pippan is used to quantitatively measure RICC [20]. The total maximum level of RICC, $\left(\frac{\delta_{\mathrm{cl}}}{\delta_{\max }}\right)_{\text {RICC }}$, can be expressed as follows:

$$
\left(\frac{\delta_{\mathrm{cl}}}{\delta_{\max }}\right)_{\text {RICC }}=\operatorname{l\eta } \sqrt{\left(\mathrm{R}_{\theta}^{2}-1\right)}+\frac{3 \eta\left(\mathrm{R}_{\theta}-1\right)}{\left[\sqrt{6}+3\left(R_{\theta}-1\right)\right]}
$$

where $C \approx 10^{-1}$ is a dimensionless constant independent of material, $R_{\theta}=\cos ^{-1}(\bar{\theta})$, is the arithmetic mean of the angle that dictates the crack deflection with crack propagation (Figure $7 \mathrm{~b}$ ). $\eta$ is a parameter that strongly depends on the size ratio, $S R=\mathrm{dm} / \mathrm{rp}$ where $\mathrm{dm}$ is the mean grain size and $\mathrm{rp}$ is the static plastic zone size. Static plastic zone size varies depending on the maximal applied intensity factor as a function of the applied stress amplitude and the crack length. Therefore, the value of $\eta$ differs for different stress amplitudes and, moreover, significantly changes during crack propagation. To assess the values of $\eta$ at various crack lengths, the following equation [21] is applied:

$$
\eta=\exp \left[-(0.886 \mathrm{rp} / \mathrm{dm})^{2.2}\right]
$$


(a)

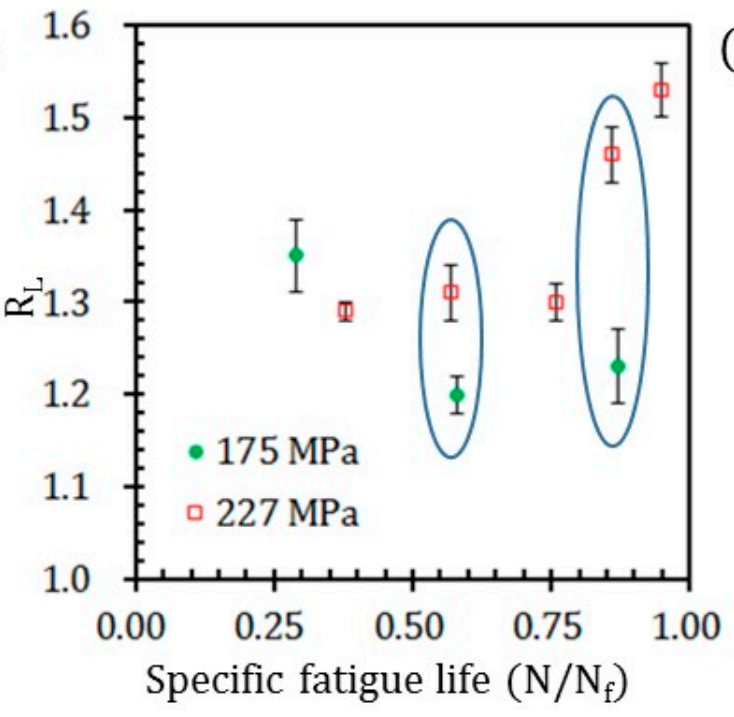

(b)

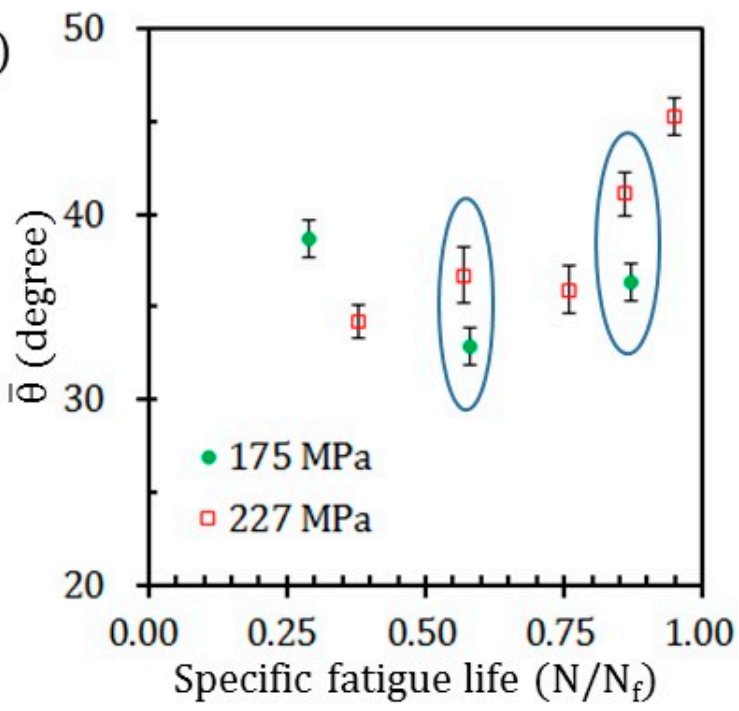

Figure 7. Roughness parameters of samples tested at the stress of 175 and $227 \mathrm{MPa}$ based on the surface crack path profile: (a) Linear roughness parameter, $\mathrm{R}_{\mathrm{L}}$; (b) Arithmetic mean of the deflection angle, $(\bar{\theta})$. Specific fatigue life denotes the ratio of instantaneous fatigue life $(\mathrm{N})$ to total fatigue life $\left(\mathrm{N}_{\mathrm{f}}\right)$; the ellipses in $(\mathbf{a}, \mathbf{b})$ show a comparison at a specific point.

For a small crack length, $2 a=100 \mu \mathrm{m}$, we obtain $\eta_{175}=0.96, \eta_{227}=0.88$ and $\eta_{175} / \eta_{227}=1.09$. This means that there is still a substantial level of RICC for both stress amplitudes. For a longer crack of $2 \mathrm{a}=300 \mu \mathrm{m}$, however, the result is $\eta_{175}=0.64, \eta_{227}=0.25$ and $\eta_{175} / \eta_{227}=2.56$. Interestingly, the level of RICC for $\sigma_{\mathrm{a} 2}(=227 \mathrm{MPa})$ becomes significantly lower than that for $\sigma_{a 1}(=175 \mathrm{MPa})$. In the case of $2 \mathrm{a}=500 \mu \mathrm{m}$, it holds $\eta_{175}=0.26$, $\eta_{227}=0.014, \eta_{175} / \eta_{227}=18.6$ and the level of RICC for $\sigma_{\mathrm{a} 2}(=227 \mathrm{MPa})$ already becomes negligible. The above comparative analysis clearly shows that there is a lower level of RICC related to the higher applied stress amplitude $\sigma_{\mathrm{a} 2}(=227 \mathrm{MPa})$ for all fatigue cracks longer than $100 \mu \mathrm{m}$, which corresponds to a higher crack growth rate under the applied stress amplitude $\sigma_{\mathrm{a} 2}(=227 \mathrm{MPa})$ than that for $\sigma_{\mathrm{a} 1}(=175 \mathrm{MPa})$. This clearly explains the slow crack growth up to around $100 \mu \mathrm{m}$ of sample under the applied stress amplitude. Crack coalescence under the applied $\sigma_{\mathrm{a} 2}(=227 \mathrm{MPa})$ happened for cracks much longer than $100 \mu \mathrm{m}$ with the level of RICC lower (or even negligible) compared to that under the stress $\sigma_{\mathrm{a} 1}(=175 \mathrm{MPa})$. Therefore, crack coalescence is considered to compensate for lower RICC level for $\sigma_{\mathrm{a} 2}(=227 \mathrm{MPa})$. On the other hand, the crack coalescence could compensate for the retardation of crack growth rate caused by a longer crack path due to a higher tortuosity (i.e., zig-zag growth) of the crack when $\sigma_{\mathrm{a} 2}(=227 \mathrm{MPa})$. This retardation is considered to be directly proportional to the linear roughness ratio, $\mathrm{R}_{\mathrm{L} 175} / \mathrm{R}_{\mathrm{L} 227}$ [21]. Indeed, the kinking geometry does not change the level of the maximum shear stress ahead of the crack front; therefore, the related decrease of $\mathrm{K}_{\mathrm{Ia}}$ (geometrical shielding) has no considerable effect on the crack growth rate [22].

\section{Conclusions}

Fatigue crack growth behaviour such as crack propagation and its features, roughnessinduced crack closure and fatigue striation with respect to various stress amplitudes (175, 200 and $227 \mathrm{MPa}$ ), were studied here for CP Ti. The followings are the main outcomes of the investigation:

- Number of cycles to failure increased from $1.05 \times 10^{5}$ to $3.40 \times 10^{5}$ to $6.94 \times 10^{5}$ with decreasing stress amplitude from 227 to 200 to $175 \mathrm{MPa}$, respectively. Throughout the total life cycle, most of the cycle was spent on crack growth for all stress conditions. It was found that cracks initiated from the surface of the samples.

- A single fatigue crack was observed to be responsible for failure of sample tested at $175 \mathrm{MPa}$. At $200 \mathrm{MPa}$, two main cracks, and at $227 \mathrm{MPa}$ three cracks were recorded for 
fatigue failure. Each of the cracks at $227 \mathrm{MPa}$ propagated via sub-crack coalescence. In all conditions, crack deflection, crack branching and slip bands, which are characteristics of crack closure, were noticed. Beyond the initial $100 \mu \mathrm{m}$, crack growth rate for the $227 \mathrm{MPa}$ sample was higher than that of the $175 \mathrm{MPa}$ sample.

- $\quad$ RICC calculation for crack lengths of 100, 300 and $500 \mu \mathrm{m}$ under the 175 and $227 \mathrm{MPa}$ conditions showed a remarkable outcome. Up to $500 \mu \mathrm{m}$ crack length a substantial RICC was calculated at $175 \mathrm{MPa}$, while the same level of RICC for $227 \mathrm{MPa}$ was found up to $300 \mu \mathrm{m}$. Beyond $100 \mu \mathrm{m}$, the RICC level for $175 \mathrm{MPa}$ displayed a higher value than at $227 \mathrm{MPa}$. This gives a reasonable explanation for the abrupt increase of crack growth rate under the $227 \mathrm{MPa}$ condition.

Author Contributions: Conceptualization, M.A. and D.R.; validation, M.A.; investigation, M.A., M.S.I.; resources, R.C., S.Y.; data curation, M.A.; writing-original draft preparation, M.A., M.S.I.; writing — review and editing, D.R.; visualization, M.A., M.S.I.; supervision, D.R.; funding acquisition, M.A. All authors have read and agreed to the published version of the manuscript.

Funding: This project has received funding from Enterprise Ireland and the European Union's Horizon 2020 Research and Innovation Programme under the Marie Sklodowska-Curie grant agreement No 847402.

Institutional Review Board Statement: Not applicable.

Informed Consent Statement: Not applicable.

Data Availability Statement: Not applicable.

Conflicts of Interest: The authors declare no conflict of interest.

\section{References}

1. Takao, K.; Kusukwa, K. Low-cycle fatigue behaviour of commercially pure titanium. Mater. Sci. Eng. A 1996, $213,81-85$. [CrossRef]

2. Wang, S.-H. A study on the change of fatigue fracture mode in two titanium alloys. Fatigue Fract. Eng. Mater. Struct. 1998, 21, 1077-1087. [CrossRef]

3. Suresh, S. Crack deflection: Implications for the growth of long and short fatigue cracks. Metall. Trans. A 1983, 14, 2375-2385. [CrossRef]

4. Ogawa, T.; Tokaji, K.; Ohya, K. The effect of microstructure and fracture surface roughness on fatigue crack propagation in a Ti-6A1-4V alloy. Fatigue Fract. Eng. Mater. Struct. 1993, 16, 973-982. [CrossRef]

5. Llorca, J. Roughness-induced fatigue crack closure: A numerical study. Fatigue Fract. Eng. Mater. Struct. 1992, 15, 655-669. [CrossRef]

6. Wang, S.-H.; Müller, C. Fracture surface roughness and roughness-induced fatigue crack closure in Ti-2.5 wt \% Cu. Mater. Sci. Eng. A 1998, 255, 7-15. [CrossRef]

7. Suresh, S. Fatigue crack deflection and fracture surface contact: Micromechanical models. Metall. Trans. A 1985, 16, 249-260. [CrossRef]

8. Antunes, F.V.; Ramalho, A.; Ferreira, J.M. Identification of fatigue crack propagation modes by means of roughness measurements. Int. J. Fatigue 2000, 22, 781-788. [CrossRef]

9. Ritchie, R.O.; Suresh, S. Some considerations on fatigue crack closure at near-threshold stress intensities due to fracture surface morphology. Metall. Trans. A 1982, 13, 937-940. [CrossRef]

10. Ding, Y.S.; Tsay, L.W.; Chen, C. The effects of hydrogen on fatigue crack growth behaviour of Ti-6Al-4V and Ti-4.5Al-3V-2Mo-2Fe alloys. Corros. Sci. 2009, 51, 1413-1419. [CrossRef]

11. Okayasu, M.; Chen, D.; Wang, Z. Experimental study of the effect of loading condition on fracture surface contact features and crack closure behavior in a carbon steel. Eng. Fract. Mech. 2006, 73, 1117-1132. [CrossRef]

12. Student, O.Z.; Cichosz, P.; Szymkowski, J. Correlation between the fracture roughness and fatigue threshold of high-temperature degraded steel. Mater. Sci. 1999, 35, 796-801. [CrossRef]

13. Jiang, X.P.; Wang, X.Y.; Li, J.X.; Li, D.Y.; Man, C.S.; Shepard, M.J.; Zhai, T. Enhancement of fatigue and corrosion properties of pure Ti by sandblasting. Mater. Sci. Eng. A 2006, 429, 30-35. [CrossRef]

14. Wojcik, C.C.; Chan, K.S.; Koss, D.A. Stage I fatigue crack propagation in a titanium alloy. Acta Metall. 1988, 36, 1261-1270. [CrossRef]

15. Ismarrubie, Z.N.; Sugano, M. Environmental effects on fatigue failure micromechanisms in titanium. Mater. Sci. Eng. A 2004, 386, 222-233. [CrossRef] 
16. Nikitin, A.; Bathias, C.; Palin-Luc, T.; Shanyavskiy, A. Crack path in aeronautical titanium alloy under ultrasonic torsion loading. Frat. Integrita Strutt. 2015, 10, 213-222. [CrossRef]

17. Fintová, S.; Arzaghi, M.; Kuběna, I.; Kunz, L.; Sarrazin-Baudoux, C. Fatigue crack propagation in UFG Ti grade 4 processed by severe plastic deformation. Int. J. Fatigue 2017, 98, 187-194. [CrossRef]

18. Małecka, J.; Rozumek, D. Metallographic and Mechanical Research of the O-Ti ${ }_{2}$ AlNb Alloy. Materials 2020, 13, 3006. [CrossRef]

19. Gray, G.T.; Williams, J.C.; Thompson, A.W. Roughness-Induced Crack Closure: An Explanation for Microstructurally Sensitive Fatigue Crack Growth. Metall. Trans. A 1983, 14, 421-433. [CrossRef]

20. Pokluda, J.; Pippan, R. Analysis of roughness-induced crack closure based on asymmetric crack-wake plasticity and size ratio effect. Mater. Sci. Eng. A 2007, 462, 355-358. [CrossRef]

21. Pokluda, J.; Sandera, P. Micromechanisms of Fracture and Fatigue; Springer: London, UK, 2010.

22. Pippan, R. The crack driving force for fatigue crack propagation. Eng. Fract. Mech. 1993, 44, 821-829. [CrossRef] 